\title{
Molecular Characterization of 16S rRNA and Internal Transcribed Spacer (ITS) Regions of Aeromonas spp. Isolated from Cultured Freshwater Fishes in Malaysia
}

\author{
K.P. Diyana-Nadhirah ${ }^{1}$ and M.Y. Ina-Salwany ${ }^{1,2^{*}}$ \\ ${ }^{1}$ Department of Aquaculture, Faculty of Agriculture, Universiti Putra Malaysia, 43400, \\ Serdang, Selangor, Malaysia \\ ${ }^{2}$ Laboratory of Marine Biotechnology, Institute of Bioscience, Universiti Putra Malaysia, \\ 43400 Serdang, Selangor, Malaysia \\ *Corresponding author
}

\section{Keywords}

Aeromonas spp., PCR, 16S rRNA gene, ITS gene, neighbor-joining, Phylogenetic analysis.

\section{Article Info}

Accepted:

15 August 2016

Available Online:

10 September 2016

\section{A B S T R A C T}

The Aeromonas spp., which are found mostly in freshwater fishes are known to cause uncontrolled disease outbreak in aquaculture system. In the present study, twenty-two of Aeromonas spp. strains isolated from diseased freshwater fishes were identified using the $16 \mathrm{~S}$ ribosomal RNA (rRNA) and internal transcribed spacer (ITS) regions gene amplification where they produced a $1500 \mathrm{bp}$ and 10001200 bp amplicon each. Phylogenetic analysis with BLASTn and 16S rRNA neighbor-joining bootstrapping methods revealed that all strains were identified up to genus level with 15 strains were classified as Aeromonas hydrophila ( $A$. hydrophila) and the rest were Aeromonas veronii (A. veronii). Further ITS gene analysis disclosed strains identification up to species level; A. hydrophila (14 strains) and A. veronii (8 strains). These rapid DNA-based detection methods are simple, easy to perform and faster in identifying Aeromonas spp., thus are absolutely efficient for regular monitoring of Aeromonas spp. in a potential outbreak situation.

\section{Introduction}

Aeromonas are divided into three species that are phenotypically and genetically differed namely Aeromonas hydrophila, A.caviae and A.sobria (Corry et al., 2003). The presence of Aeromonas spp. in aquaculture system has been evidenced to induce outbreaks with high mortality rates in cultured fish, where the group that commonly causes infection and diseases is associated to a psychrophilic and non-motile strain known as Aeromonas salmonicida (Janda and Abbott, 2010).

Development of DNA-based molecular techniques in identifying bacterial species has ignited a great influence on prokaryotes identification based on 16S rRNA gene analysis (Rossello-Mora and Amann, 2001). Moreover, the 16S rRNA gene classification has been widely accepted and used for the 
detection and delineation of Aeromonas spp. in aquaculture field. The $16 \mathrm{~S}$ rRNA is very useful in classifying Aeromonas spp. up to genus level (Ludwig et al., 1998). Previous studies demonstrated that more than $70 \%$ of genomic similarities were discovered in organisms that shared $97 \%$ of their $16 \mathrm{~S}$ rRNA sequences (Stackebrandt and Goebel, 1994; Garcia-Martinez et al., 1999).

To date, an internal transcribed spacer-PCR (ITS-PCR) method based on the different distances separating conserved functional RNA genes is applied to classify species within genus (Magni, 2010). According to Singh et al. (2012), amplification of ITS region which flanking between $16 \mathrm{~S}-23 \mathrm{~S}$ rDNA regions will produce distinctive DNA banding patterns that could recognize microorganism up to species level (Jensen $e t$ al., 1993; Gurtler and Stanisich,1996).

In our study, we aimed to characterize molecularly local of Aeromonas isolated by using two genes, 16S Rrna and ITS that can be used as phylomarker genes combination in diagnosis Aeromonas infected fish.

\section{Materials and Methods}

\section{Bacterial Cultures, Morphological and Biochemical Characterization}

Twenty-two strains of Aeromonas spp. (Clarias spp., Pangasius spp., and Oreochromis spp.) culture isolated from diseased freshwater fishes in different places in Malaysia were provided by Malaysian National Fish Health Research Centre (Nafish), Batu Maung, Penang, Malaysia (Table 1). These cultures were maintained on tryptic soy agar (TSA; Difco, USA.) plates at $37^{\circ} \mathrm{C}$ for $18-24$ hours. Single colonies from TSA plates were retrieved in tryptic soy broth (TSB; Difco, USA) by incubation for 18 hours at $200 \mathrm{rpm}$.
All Aeromonas spp. strains were then subjected to biochemical identification including Gram-staining, catalase and oxidase tests (Abbott et al., 2003).

\section{DNA Extraction}

A single colony from culture was grown overnight in $5 \mathrm{ml} \mathrm{TSB}$ at $37^{\circ} \mathrm{C}, 200 \mathrm{rpm}$. Total genomic DNA of each strain was extracted with GeneJet Genomic DNA Purification Kit (ThermoFischer Scientific Inc, USA) according to the manufacturer's instructions. The concentration of purified DNA was measured by using BioPhotometer Plus (Eppendorf, Germany).

\section{Polymerase Chain Reaction Amplification and DNA Sequencing}

All extracted total genomic DNA from the respective Aeromonas spp. strains was used as templates in the polymerase chain reaction (PCR) amplification to amplify the 16S rRNA and ITS genes.

The primer pairs, Forward (5'GAGTTTGATCCTGGCTCAG-3') and Reverse (5'-GGT TACCTTGTTACGACT3 ') were used for amplifying the $16 \mathrm{~S}$ rDNA region of the Aeromonas spp. These primers were expected to amplify a $1500 \mathrm{bp}$ amplicon. PCR was carried out in a $25 \mu \mathrm{l}$ reaction volume containing $1 \mu \mathrm{L}$ of $100 \mathrm{ng}$ genomic DNA template, $5 \mu \mathrm{L}$ of $5 \mathrm{X}$ PCR Buffer, $2 \mu \mathrm{L}$ of $2 \mathrm{mM} \mathrm{MgCl} 2,2 \mu \mathrm{L}$ of 200 $\mu \mathrm{M} \quad \mathrm{dNTP}, \quad 0.5 \mu \mathrm{L}$ Taq Polymerase (Promega, USA), $12.5 \mu \mathrm{l}$ of sterile distilled water and $1 \mu \mathrm{L}$ of $20 \mathrm{pmol}$ of each primers (First Base Laboratories, Malaysia). PCR amplification was performed with the following protocol; $94{ }^{\circ} \mathrm{C}$ for $10 \mathrm{~min} ; 35$ cycles of $94{ }^{\circ} \mathrm{C}$ for $1 \mathrm{~min}, 54{ }^{\circ} \mathrm{C}$ for $1 \mathrm{~min}$, and $72{ }^{\circ} \mathrm{C}$ for $90 \mathrm{sec}$; and a final extension of $72{ }^{\circ} \mathrm{C}$ for $10 \mathrm{~min}$. 
For ITS gene PCR amplification, primers user in this study were the ITS Forward (5'CGGTGAATACGTTCCCGGGYCTTG-3') and the ITS Reverse (5'-TTTCRCCT TTCCCTCACGGTA-3').

These primers were expected to amplify a 1000-1200 bp amplicon. PCR was performed as follow; $94{ }^{\circ} \mathrm{C}$ for $3 \mathrm{~min} ; 35$ cycles of $94{ }^{\circ} \mathrm{C}$ for $30 \mathrm{sec}, 50{ }^{\circ} \mathrm{C}$ for $1 \mathrm{~min}$, and $72{ }^{\circ} \mathrm{C}$ for $90 \mathrm{sec}$; and a final extension of $72^{\circ} \mathrm{C}$ for $5 \mathrm{~min}$. All PCR amplification was performed using Mastercycler Gradient PCR system (Eppendorf, Germany). Negative control without template was included in every set of reactions.

Detection of PCR products was carried out with $1 \%$ agarose gel electrophoresis for 60 min at 70 volts. All PCR products were purified using GeneJET Gel Extraction Kit according to the manufacturer's instructions (Thermo Fischer Scientific Inc, USA). The purified DNAs were then sent for sequencing (First Base Laboratories Sdn. Bhd., Malaysia).

\section{Sequence Alignment and Phylogenetic Tree Analysis}

DNA sequences were compared to other known sequences from GenBank database using BLASTn (Nucleotide Basic Local Alignment Search Tool) searches of National Center for Biotechnology Institute (http://blast.st-va.ncbi.nlm.nih.gov/Blast.

cgi). All sequences were tanalyzed using BioEdit version 7.0 multiple alignment program (Hall, 2005).

Phylogenetic analysis of the aligned sequences was constructed using a neighbour-joining (NJ) method with 1000 replications utilizing MEGA 5.0 software (Tamura et al., 2011).

\section{Results and Discussion}

\section{Morphological and Biochemical Characterization}

Results from biochemical identification showed that all strains produced typical characteristics of Aeromonas spp., which were Gram-negative, motile and rod shaped in morphology. These strains were verified up to species level as $A$. hydrophila, $A$. sobria, and A. hydrophila/caviae using the API 20E system (Table 1) which in line with report by, Soler et al., 2003; Ormen et al., 2005).

\section{$16 S$ rRNA Gene Amplification and Phylogeny Analysis}

Amplification of $16 \mathrm{~S}$ rRNA gene in all Aeromonas spp. strains each produced a 1500 bp amplicon as expected (Figure 1) as reported by Martinez-Murcia et al., 1992. Our BLASTn results of $16 \mathrm{~S}$ Rrna gene showed all Aeromonas spp. strains revealed that 15 strains were classified as $A$. hydrophila and 7 strains were identical to $A$. veronii, all with 98-100\% similarities to GenBank nucleotide sequences database.

The neighbor-joining (NJ) 16S rRNA sequence phylogenetic tree showed a branching pattern that clearly separates all our Aeromonas spp. and reference strains into 2 major clusters, G1 and G2 (Figure 2). Based on the phylogenetic tree, Aeromonas spp. strains PK53S, PK60S and PK60L were grouped together with $A$. hydrophila reference strains from GenBank (accession Nos. GU563992, AB610604, FN997617 and GQ70996) with $98 \%$ to $100 \%$ bootstrap values (sub-group G1 (i)). The second cluster, G2 consisted of 4 minor sub-groups that are G2 (i), G2 (ii), G2 (iii) and G2 (iv). Sub-group G2 (i) comprised of the Aeromonas spp. strains K1B and PSM545, 
while sub-group G2 (iii) showed 8 Aeromonas spp. strains which were clustered together with the reference strain, Aeromonas jandeii (accession No. JF713702). The last sub-group, G2 (iv) consisted most of our Aeromonas spp. strains that were clustered together (TPK5K, TTG6E， TTG11B， TPK2K， TTG11E, KTG3Sb, TTG9K, PK159S and TFT3B).

\section{ITS Gene Amplification And Phylogeny Analysis}

In this study, amplification of the $16 \mathrm{~S}-23 \mathrm{~S}$ ITS region on all Aeromonas spp. strains each yielded an amplicon of 1000-1200 bp (Figure 3). The results were in line with previous published findings that reported these diverse pattern bands (1000-1200 bp) are due to the tRNA number encoding gene and the number of copy ribosomal unit contained by the ITS (Singh et al., 2012).

The neighbor-joining phylogenetic tree of Aeromonas species based on the ITS had shown that the neighbor-joining tree has formed branches that labeled as G1 and G2 (Figure 4). The group G1 has formed the branch that consists of two samples (PSM545 and TPK6K). These two samples have been cluster into as one group (G1) due to the similarity of gene sequences. Based on $\mathrm{G} 2$ have formed two branches which are the G2 (i) and G2 (ii). The G2 (i) was formed a cluster known as G2 (a) consist of six samples clustered together. G2 (a) are clustered together with references strain of Aeromonas hydrophila (HM856362.1). The G2 (e) shown a sample of TTG6E was similar to Aeromonas caviae (AF198382.1).

The largest cluster group was G2 (f) where this cluster formed two branches which is known as G2 (f) and G2 (f) b. The variation in gene sequences are very high (mutation) but there were some regions for conserved gene sequences (the point shows similarities of sequences). According to previous study by Kong et al. (1999), the heterogeneities (sequence and length polymorphisms) were observed based on the alignment in the central region of the spacers and mention that this $16 \mathrm{~S}-23 \mathrm{~S}$ (ITS) that the profiling of rDNA has potential as a quick rDNA typing and strain detection tool for Aeromonas species.

Kong et al., (1999) also have stated that in his study that, the highest similarity was observed amongst three Aeromonas hydrophila (95\% - $99 \%)$. This can be refer to the Berridge et al. (2001) and Hassan et al. (2001), the ITS region has been useful to identified the species level as in instance relative genus analysis of the Streptococcus and Staphylococcus.

Comparison between biochemical tests, 16S rRNA and ITS gene analysis for identification and characterization of Aeromonas spp. Strains

The comparison of phenotypic and genetic identification of 22 Aeromonas strains isolates from freshwater fishes species revealed in Table 2 . Biochemical test results towards the samples mostly detected the $59.1 \%(13 / 22)$ of Aeromonas sobria and $36.4 \%(8 / 22)$ of Aeromonas hydrophilal caviae. Based on 16S rRNA gene sequence results, showed that most of the detection were $63.6 \%$ (14/22) from Aeromonas hydrophila, $18.2 \%$ (4/22) from Aeromonas hydrophila/veronii and $18.2 \%$ (4/22) from Aeromonas veronii.

ITS gene sequences showed that most of the detection comes from $63.6 \%(14 / 22)$ of Aeromonas hydrophila and $36.4 \%(8 / 22)$ of Aeromonas veronii. 
Table.1 Aeromonas spp. cultures used in this study (2010-2013).

\begin{tabular}{|c|c|c|c|c|c|c|c|c|}
\hline \multirow[t]{2}{*}{ No. } & \multirow{2}{*}{$\begin{array}{c}\text { Strain } \\
\text { reference }\end{array}$} & \multirow[b]{2}{*}{ Source } & \multirow[b]{2}{*}{ Location } & \multicolumn{5}{|c|}{ Morphological and Biochemical Characterization } \\
\hline & & & & Gram Stain & Catalase & Oxidase & API 20E system & $\%$ \\
\hline 1 & KTG 3S(b) & Clarias spp. & Tasek Gelugor & -ve (rod) & $+\mathrm{ve}$ & $+\mathrm{ve}$ & A. sobria & 99.2 \\
\hline 2 & K1B & Clarias spp. & Fri Gelami-Lemi & -ve (rod) & -ve & +ve & A.hydrophila & - \\
\hline 3 & PHE 578L & Pangasius spp. & Pahang & -ve & -ve & +ve & A. sobria & 99.4 \\
\hline 4 & PK 159S & Pangasius spp. & Pahang & -ve (short, rod) & -ve & +ve & A. sobria & 99.2 \\
\hline 5 & PK 60L & Pangasius spp. & Pahang & -ve (rod) & $+\mathrm{ve}$ & + ve & A.hrdrophila/caviae & 99.7 \\
\hline 6 & PK 60S & Pangasius spp. & Pahang & -ve (rod) & +ve & +ve & A.hrdrophila/caviae & 99.7 \\
\hline 7 & PK 53S & Pangasius spp. & Pahang & -ve (rod) & +ve & + ve & A.hrdrophila/caviae & 99.7 \\
\hline 8 & PSM 545 & Pangasius spp. & Pahang & -ve (short, rod) & +ve & $+\mathrm{ve}$ & A. sobria & 83.8 \\
\hline 9 & TPK2B & Oreochromis spp. & Pantai Kamloon & - & - & - & A.sobria & 99.2 \\
\hline 10 & TPK4B & Oreochromis spp. & Pantai Kamloon & - & - & - & A.sobria & 99.2 \\
\hline 11 & ТРК5B & Oreochromis spp. & Pantai Kamloon & - & - & - & A.sobria & 94.9 \\
\hline 12 & TTG9K & Oreochromis spp. & Tasik Gelugor & - ve & $+\mathrm{ve}$ & +ve & A.hydrophila/caviae & 95.7 \\
\hline 13 & TFT 3B & Oreochromis spp. & Felda Titi & -ve & $+v e$ & $+v e$ & A.sobria & - \\
\hline 14 & TPK 5K & Oreochromis spp. & Pantai Kamloon & - & - & - & A.sobria & 94.9 \\
\hline 15 & TTG $11 \mathrm{~K}$ & Oreochromis spp. & Tasik Gelugor & -ve & +ve & $+\mathrm{ve}$ & A.hydrophila/caviae & 99.7 \\
\hline 16 & TFT 3K & Oreochromis spp. & Felda Titi & - ve & +ve & +ve & A.sobria & - \\
\hline 17 & TFT 3E & Oreochromis spp. & Felda Titi & -ve & + ve & $+\mathrm{ve}$ & A.sobria & - \\
\hline 18 & TPK 2K & Oreochromis spp. & Pantai Kamloon & -ve & $+\mathrm{ve}$ & +ve & A.sobria & 94.9 \\
\hline 19 & TTG11E & Oreochromis spp. & Tasik Gelugor & -ve & + ve & $+\mathrm{ve}$ & A.hydrophila/caviae & 95.7 \\
\hline 20 & TTG6E & Oreochromis spp. & Tasik Gelugor & -ve & +ve & $+v e$ & A.hydrophila/caviae & 95.7 \\
\hline 21 & TTG11B & Oreochromis spp. & Tasik Gelugor & -ve & -ve & +ve & A.hydrophila/caviae & 99.7 \\
\hline 22 & TPK 6K & Oreochromis spp. & Pantai Kamloon & - & - & - & A.sobria & 82.2 \\
\hline
\end{tabular}


Table. 2 Comparison of phenotypic and genetic identification of 22 Aeromonas spp. strains isolates from freshwater fish species.

\begin{tabular}{|c|c|c|c|c|}
\hline \multirow[t]{2}{*}{ No. } & \multirow[t]{2}{*}{ Strain } & \multicolumn{3}{|c|}{ Table 3: Taxonomic identification (species name) based on } \\
\hline & & Biochemical Test & 16S rRNA gene sequences & ITS gene sequences \\
\hline 1 & KTG 3S(b) & A. sobria & A. hydrophila/veronii & A. veronii \\
\hline 2 & K 1 B & A. hydrophila & A. hydrophila & A. hydrophila \\
\hline 3 & PHE 578L & A. sobria & A. hydrophila & A. veronii \\
\hline 4 & PK159S & A. sobria & A. hydophila & A. veronii \\
\hline 5 & PK60L & A. hrdrophila/caviae & A. hyrophila & A. hydrophila \\
\hline 6 & PK60S & A. hrdrophila/caviae & A. hydrophila & A. hydrophila \\
\hline 7 & PK53S & A. hrdrophila/caviae & A. hydrophila & A. hydrophila \\
\hline 8 & PSM545 & A. sobria & A. hydrophila & A. hydrophila subsp. hydrophila \\
\hline 9 & TPK2B & A. sobria & A. hydrophila & A. veronii \\
\hline 10 & TPK4B & A. sobria & A. hydrophila & A. veronii \\
\hline 11 & TPK5B & A. sobria & A. hydrophila & A. hydrophila \\
\hline 12 & TTG9K & A. hydrophila/caviae & A. veronii & A. hydrophila subsp. hydrophila \\
\hline 13 & TFT3B & A. sobria & A. hydrophila & A. hydrophila subsp. hydrophila \\
\hline 14 & TPK5K & A. sobria & A. hydrophila & A. veronii \\
\hline 15 & TTG11K & A. hydrophila/caviae & A. hydrophila/veronii & A. hydrophila subsp. hydrophila \\
\hline 16 & TFT3K & A. sobria & A. veronii & A. hydrophila subsp. hydrophila \\
\hline 17 & TFT3E & A. sobria & A. veronii & A. hydrophila subsp. hydrophila \\
\hline 18 & TPK2K & A. sobria & A. veronii & A. veronii \\
\hline 19 & TTG11E & A. hydrophila/caviae & A. hydrophila/veronii & A. veronii \\
\hline 20 & TTG6E & A. hydrophila/caviae & A. hydrophila & A. hydrophila subsp. hydrophila \\
\hline 21 & TTG11B & A. hydrophila/caviae & A. hydrophila/veronii & A. hydrophila subsp. hydrophila \\
\hline 22 & TPK6K & A. sobria & A. hydrophila & A. hydrophila subsp. hydrophila \\
\hline
\end{tabular}


Fig.1 Agarose gel electrophoresis analysis of PCR amplification of the 16S rRNA gene of Aeromonas spp. strains.

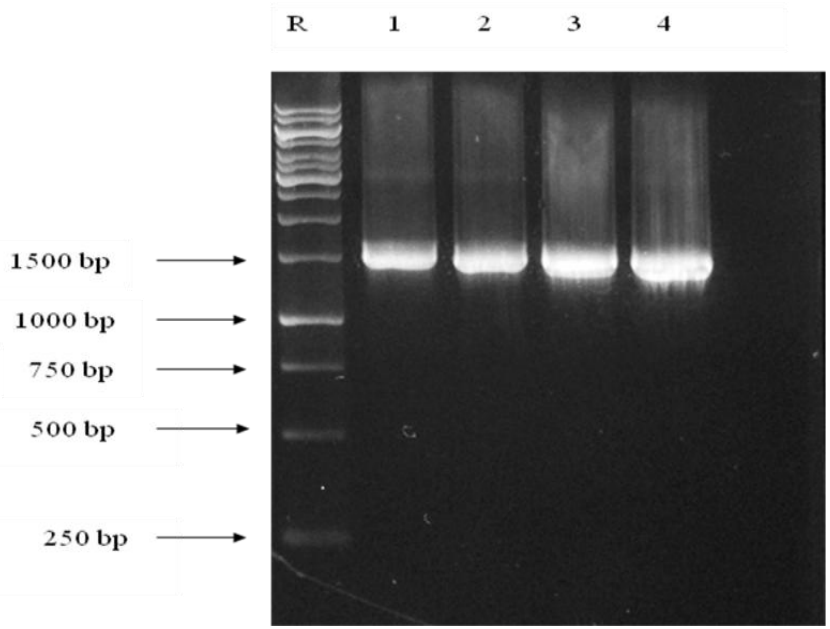

Lane R: Gene ruler DNA ladder $1 \mathrm{~kb}$ (Fermentas)

Lane 1: Aeromonas spp. K1B

Lane 2: Aeromonas spp. TPK 6K

Lane 3: Aeromonas spp. TTG11B

Lane 4: Aeromonas spp. TTG6E

Lane 5: Control

Fig.2 Neighbor-joining phylogenetic tree of Aeromonas spp. from freshwater fishes and reference strains based on the $16 \mathrm{~S}$ gene sequences. Number on each node is the bootstrap value (1000 replicates). The scale bar represents 1 nucleotide substitution per 10 nucleotides.

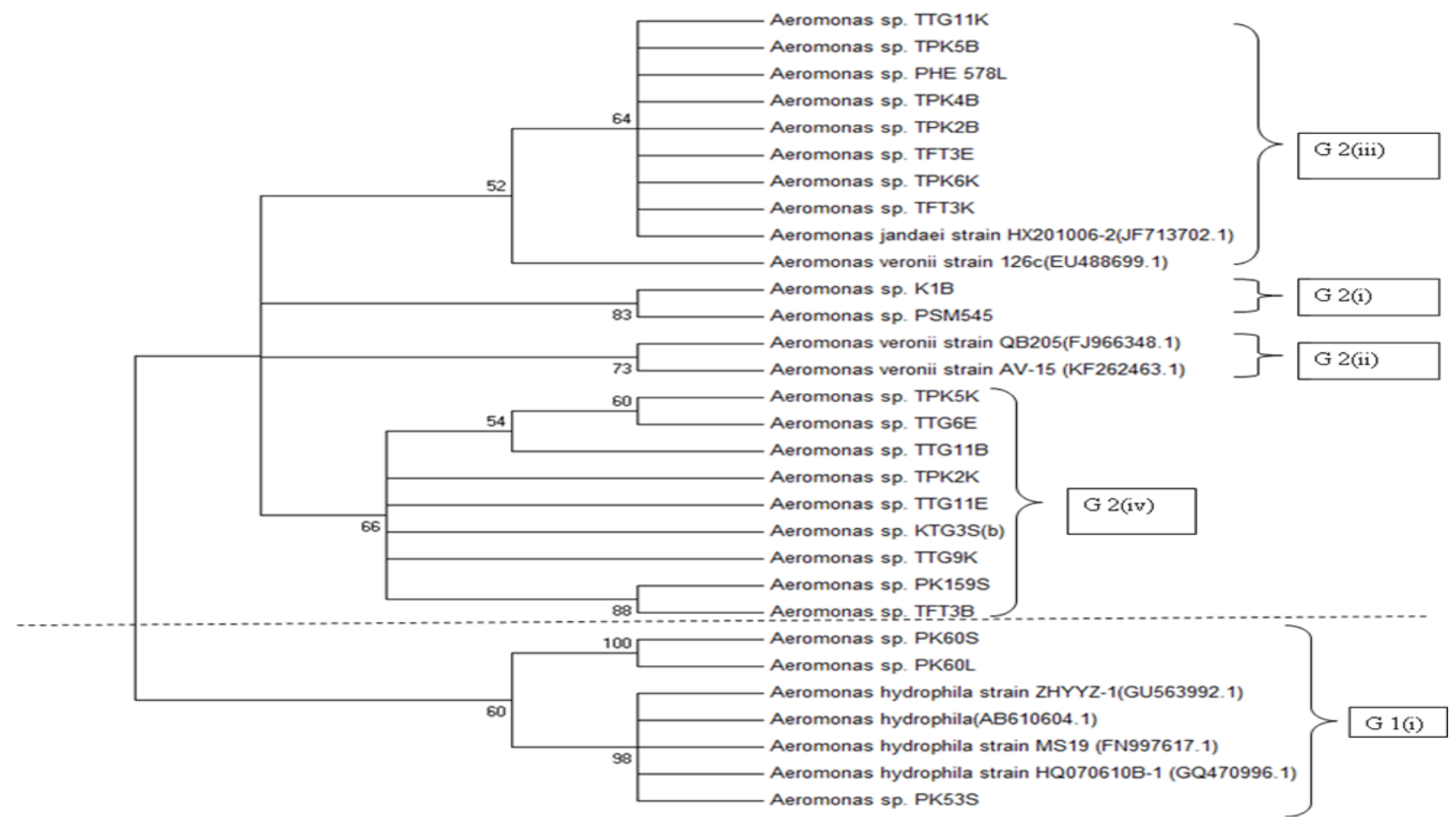


Fig.3 Agarose gel electrophoresis analysis of PCR amplification of the ITS rRNA gene of Aeromonas spp. strains.

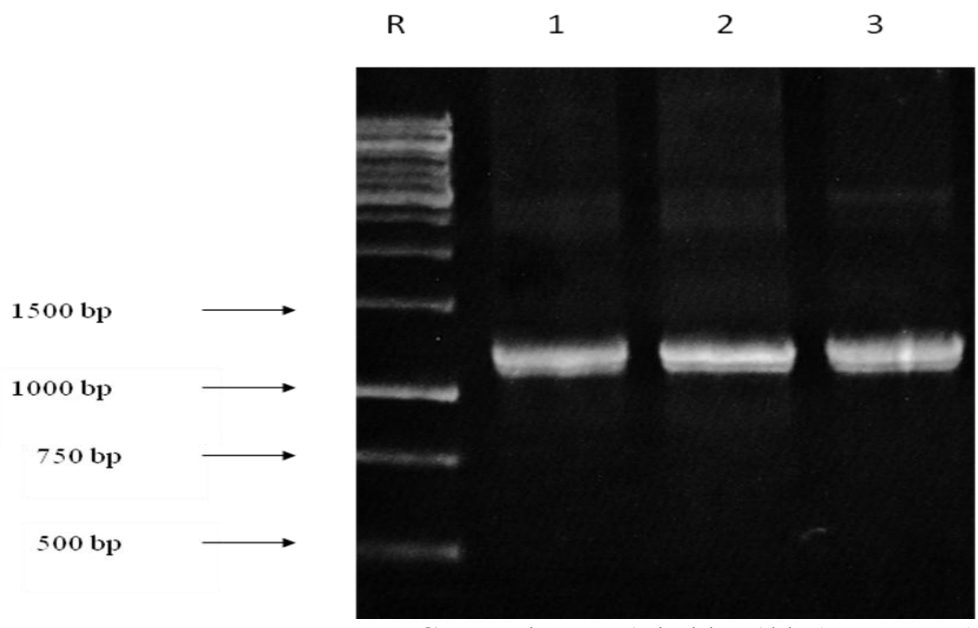

Lane R: Gene ruler DNA ladder $1 \mathrm{~kb}$ (Fermentas)

Lane 1: Aeromonas spp. KTG3S

Lane 2: Aeromonas spp. TPK2B

Lane 3: Aeromonas spp. PK159S

Fig.4 Neighbor-joining phylogenetic tree of Aeromonas spp. from freshwater fishes and reference strains based on the ITS gene sequences. Number on each node is the bootstrap value (1000 replicates). The scale bar represents 1 nucleotide substitution per 10 nucleotides.

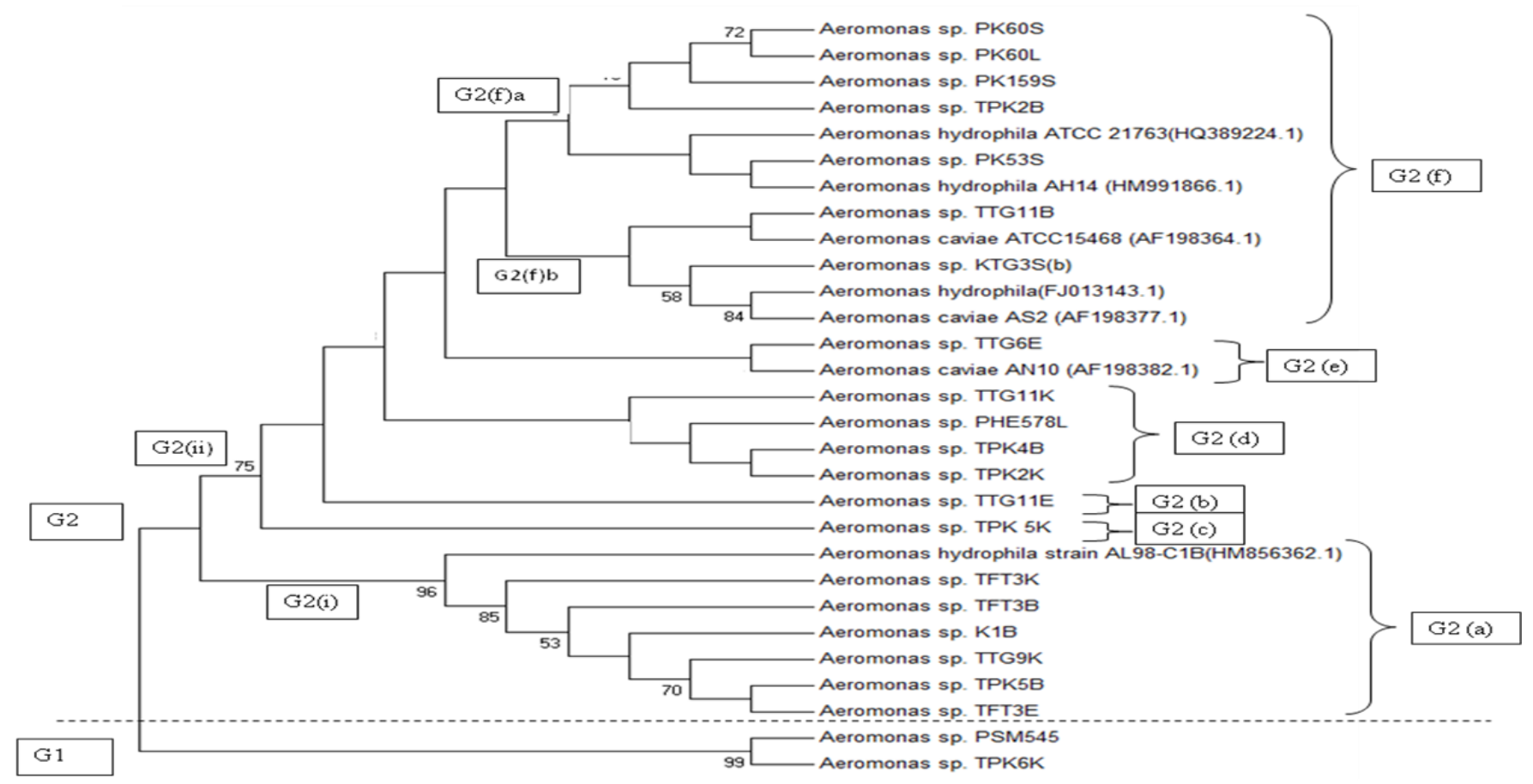


The both molecular techniques used in this study have showed there are discrepancies on the detection results from the 22 isolates compared with biochemical test. As in the previous study was highlighted that there still have discrepancies in data collected based on the molecular techniques and biochemical test (Borrell et al., 1997; Castro-Escarpulli et al., 2003). The molecular comparison between the $16 \mathrm{~S}$ rRNA gene sequences with the ITS gene sequences also shows conflict to determine up to the species level

In conclusion, in the present study, this can be conclude that the ITS can be useful tools to identify Aeromonas species until to the species level. Besides that, molecular diagnosis of fish pathogen can be analyzed using the ITS - 16S Rrna-PCR based method which proved the most reliable method in determined and identified bacterial species including Aeromonas isolates.

\section{Acknowledgements}

We thank University Putra Malaysia (UPM) and Department of Aquaculture (UPM) for the expertise and opportunities to implement this project. We are very grateful to Malaysian National Fish Health Research Centre (Nafish) in providing for the realization of this project.

\section{References}

Abbott, S.L., Cheung, W.K. and Janda, J.M. 2003. The genus Aeromonas: biochemical characteristics, atypical reactions, and phenotypic identification schemes. J. Clin. Microbiol., 41: 2348- 2357.

Amann, R.I., Lin, C., Key, R., Montgomery, L. and Stahl, D.A. 1992. Diversity among brobacter isolates: towards a phylogenetic classification. Syst. Appl. Microbiol., 15: 23-31.

Berridge, B.R., Bercovier, H. and Frelier, P.F. 2001. Streptococcus agalactiae and Streptococcus difficile 16S-23S intergenic rDNA: genetic homogeneity and species-specific PCR. Vet. Microbiol., 78: 165-173.

Borrell, N., Acinas, S.G., Figueras, M.J. and Martinez-Murcia, A.J. 1997. Identification of Aeromonas clinical isolates by restriction fragment length polymorphism of PCR-amplified 16S rRNA gene. J. Clin. Microbiol., 35: $167-1674$.

Castro-Escarpulli, G., Figueras, M.J., Aguilera-Arreola, G., Soler, L., Fernandez-Rendon, E., Aparicio, G.O. and Chacon, M.R.., 2003. Characterisation of Aeromonas spp. isolated from frozen fish intended for human consumption in Mexico. Int. J. Food Microbiol., 84(1): 41-49.

Corry, J.E.L., Curtis, G.D.W. and Baird, R.M. 2003. Handbook of Culture Media for Food Microbiology: Volume 34: Progress in Ind. Microbiology. Amsterdam, the Netherlands: Elsevier Science $B V$.

Garcia-Martinez, J., Acinas, S.G., Anton, A.I. and Rodriguez-Valera, F. 1999. Use of the $16 \mathrm{~S}-23 \mathrm{~S}$ ribosomal genes spacer region in studies of prokaryotic diversity. J. Microbiol. Methods, 36(1): 55-64.

Gurtler, V. and Stanisich, V.A. 1996. New approaches to typing and identification of bacteria using the 16S-23S rDNA spacer region. Microbiol., 142: 12551265.

Hall, T. 2005. BioEdit. Biological sequence alignment editor for Win95.

Hassan, A.A., Khan, I.U., Abdulmawjood, A. and Lammler, C., 2001. Evaluation of PCR methods for rapid identification and differentiation of 
Streptococcus uberis and Streptococcus parauberis. J. Clin. Microbiol., 39: 1618-1621.

Janda, J.M., and Abbott, S.L. 2010. The genus Aeromonas: taxonomy, pathogenicity, and infection. J. Clin. Microbiol. Rev., 23(1): 35-73.

Jensen, M.A., Webster, J.A. and Straus, N. 1993. Rapid identification of bacteria on the basis of polymerase chain reaction-amplified ribosomal DNA spacer polymorphisms. J. Appl. Environ. Microb., 59: 945-952.

Kong, R.Y.C., Pelling, A. and So, C.L. 1999. Identification of oligonucleotide primers targeted at the $16 \mathrm{~S}-23 \mathrm{~S}$ rDNA intergenic spacers for genus-and species-specific detection of Aeromonads. Marine Pollu. Bull., 38(9): 802-808.

Ludwig, W., Strunk, O., Klugbauer, S., Klugbauer, N., Weizenegger, M., Neumaier, J., Bachleitner, M. and Schleifer, K.H. 1998. Bacterial phylogeny based on comparative sequence analysis. Electrophoresis, 19: 554-568.

Magni, M.V. 2010. Detection of bacteria, viruses, parasites and fungi: Bioterrorism prevention. Springer.

Ormen, O., Granum P.E., Lassen, J. and Figueras, M.J. 2005. Lack of agreement between biochemical and genetic identification of Aeromonas spp. APMIS, 113: 203-207.

Rossello-Mora, R. and Amann, R. 2001. The species concept for prokaryotes. FEMS Microbiol. Rev., 25: 39-67.

Singh, V., Mani, I. and Chaudhary, D.K., 2012. Molecular Assessment of 16S23S rDNA Internal Transcribed Spacer Length Polymorphism of Aeromonas hydrophila. Adv. Microbiol., 2(2): 72-78.

Soler, L., Marco, F., Vila, J., Chacon, M.R., Guarro, J. and Figueras, M.J. 2003. Evaluation of two miniaturized systems, MicroScan W/A, and BBL Crystal E/NF, for identification of clinical isolates of Aeromonas spp. $J$ Clin. Microbiol., 41: 5732-5734.

Stackebrandt, E. and Goebel, B.M. 1994. Taxonomic note: a place for DNADNA re-association and 16S rRNA sequence analysis in the present species definition in Bacteriology. Int. J. Syst. Bacteriol., 44: 846-849.

Tamura, K., Peterson, D., Peterson, N., Stecher, G., Nei, M. and Kumar, S. 2011. MEGA5: molecular evolutionary genetics analysis using maximum likelihood, evolutionary distance and maximum parsimony methods. Mol. Biol. Evol., 28: 27312739.

\section{How to cite this article:}

Diyana-Nadhirah, K.P., and M.Y. Ina-Salwany. 2016. Molecular Characterization of 16S rRNA and Internal Transcribed Spacer (ITS) Regions of Aeromonas spp. Isolated from Cultured Freshwater Fishes in Malaysia. Int.J.Curr.Microbiol.App.Sci. 5(9): 431-440. doi: http://dx.doi.org/10.20546/ijcmas.2016.509.046 